\title{
Management of Non-Vital Teeth with Open Apices using MTA as an Apical Plug: Two Case Reports
}

\author{
${ }^{1}$ Sanjana A Patil, ${ }^{2}$ Avinash A Patil, ${ }^{3}$ Preeti K Dodwad \\ ${ }^{1}$ Postgraduate Student, Department of Conservative Dentistry and Endodontics, KLEVK Institute of Dental Sciences \\ Belgaum, Karnataka, India \\ ${ }^{2}$ Reader, Department of Conservative Dentistry and Endodontics, KLEVK Institute of Dental Sciences \\ Belgaum, Karnataka, India \\ ${ }^{3}$ Professor, Department of Conservative Dentistry and Endodontics, KLEVK Institute of Dental Sciences \\ Belgaum, Karnataka, India
}

Correspondence: Avinash A Patil, Reader, Department of Conservative Dentistry and Endodontics, KLEVK Institute of Dental Sciences, Nehru Nagar, Belgaum-590010, Karnataka, India, Phone: 0091-9986411627, e-mail: dravi007@ rediffmail.com

\section{ABSTRACT}

Management of non-vital teeth with open apices is a challenge to dental practitioners. In this clinical scenario, it is difficult to maintain the obturation material within the confines of root canal without encroaching into periapical area. Also, thin dentinal walls of canal is a matter of concern. These cases cannot be managed by conventional endodontic treatment and need customized treatment plan. Treatment of such teeth with calcium hydroxide may demand long time and patient compliance. But with MTA same treatment can be done in reasonably less time with predictable results. Hence, these two case reports present the use of MTA to form an apical plug in open apex followed by complete root canal obturation using thermoplasticized gutta-percha under operating microscope.

Keywords: Mineral trioxide aggregate, Open apices, Calcium hydroxide, Apexification.

\section{INTRODUCTION}

One of the aims of root canal treatment is to completely fill the root canal system in order to prevent reinfection. In teeth with incomplete root development as a consequence of pul p necrosis through trauma or caries, the absence of a natural constriction at the end of the root canal makes control of filling materials difficult. Because of the lack of apical constriction, an alternative to standard root canal treatment, apexification or root-end closure, has been advocated. ${ }^{1}$

A pexification can be defined as a method to induce a calcified barrier in a root with an open apex or the continued apical development of teeth with incomplete roots and a necrotic pulp. ${ }^{2}$ Calcium hydroxide has been the first choice material for apexification, ${ }^{3}$ with repeated changes over the course of 5 to 20 months to induce the formation of a calcific barrier. ${ }^{4}$ The unpredictable and often lengthy course of this treatment modal ity presents challenges, including the vulnerability of the temporary coronal restoration to reinfection. ${ }^{5} \mathrm{M}$ oreover, the treatment requires a high level of patient compliance. For these reasons, one visit apexification has been suggested. ${ }^{6}$

$M$ ineral trioxide aggregate (MTA) has been proposed as a material suitable for one visit apexification, ${ }^{7-9}$ as it combines biocompatibility ${ }^{10,11}$ and a bacteriostatic action ${ }^{12}$ with favorable sealing ability when used to repair root/pulp chamber perforations ${ }^{13}$ or as a root-end filling material. ${ }^{14}$ M TA offers a barrier at the end of the root canal (apical plug) in teeth with necrotic pulps and open apices ${ }^{7}$ that permits vertical condensation of warm gutta-percha in the remainder of the canal.
The use of an operating microscope may allow better control of the placement of the MTA at the end of the root canal. ${ }^{15}$

The aim of present case reports is to present the short-term follow-up results in two treated teeth with non-vital pulps and open root apices which were managed with M TA apical plug technique, placed under the operating microscope.

\section{CASE DESCRIPTION}

\section{Case Report 1}

A 21-year-old male patient presented to the Department of Conservative Dentistry and Endodontics, KLEVK Institute of Dental Sciences, Belgaum, Karnataka, India, with a mild swelling at the apical region of his maxillary right central incisor and had received incomplete endodontic treatment from some private clinic. History revealed that the patient had suffered trauma around the age of 8 years. Radiographic examination revealed an immature tooth with a wide open apex and a radiolucent area in proximity of the apex of the tooth (Fig. 1). The tooth gave no responses to thermal and electric pulp tests. Root canal treatment using M TA as an apical plug followed by obturation with thermoplasticized gutta-percha was planned.

A fter rubber dam application, a conventional endodontic access was prepared from palatal approach with 11. Initial working length was predicted by using paper point method. Then radiograph was made and working length was confirmed (Fig. 2). Gentle instrumentation was done with $\# 80 \mathrm{H}$-file in circumferential manner. Irrigation with $3 \%$ sodium hypochl orite was done throughout the shaping and cleaning procedures. Canal 


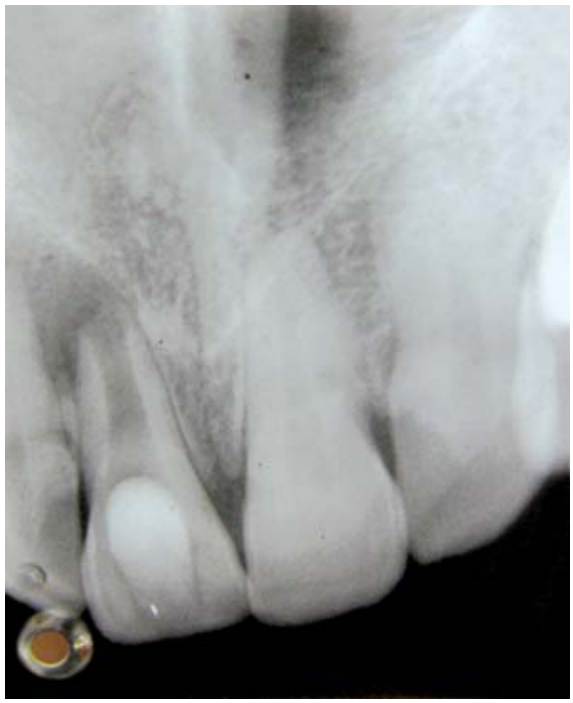

Fig. 1: Preoperative periapical radiograph (Case 1)

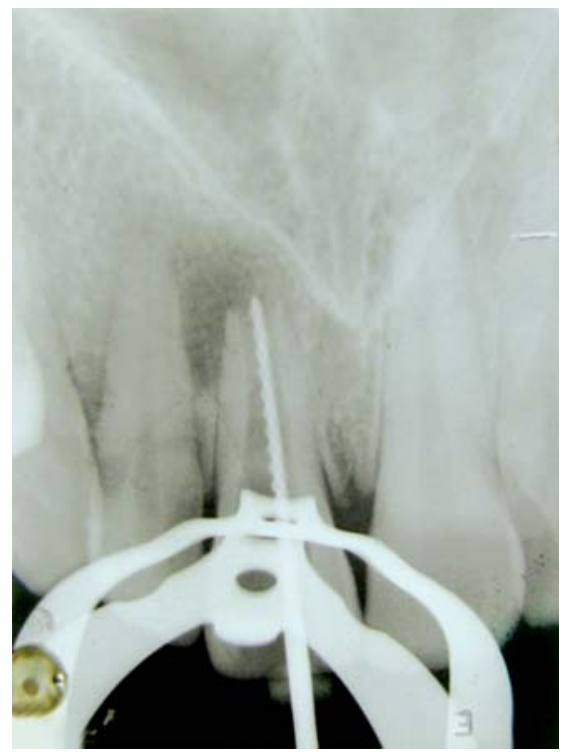

Fig. 2: Working length radiograph (Case 1)

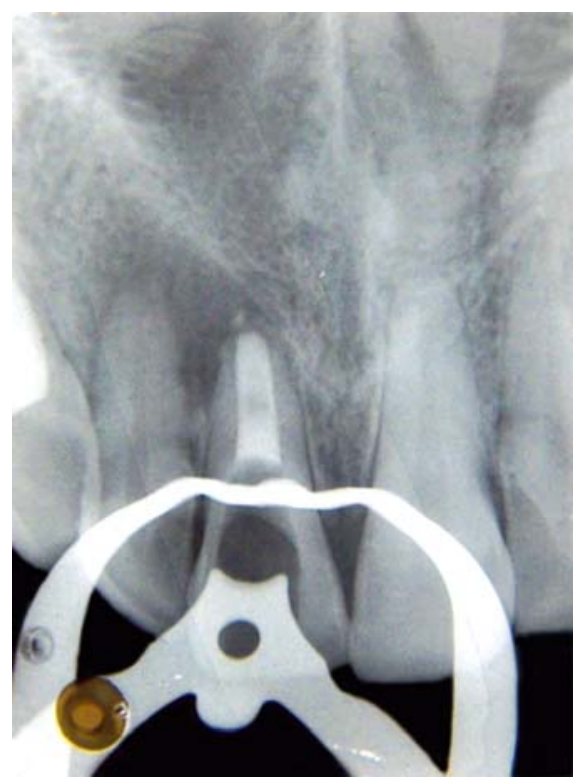

Fig. 3: Apical plug of MTA (Case 1)

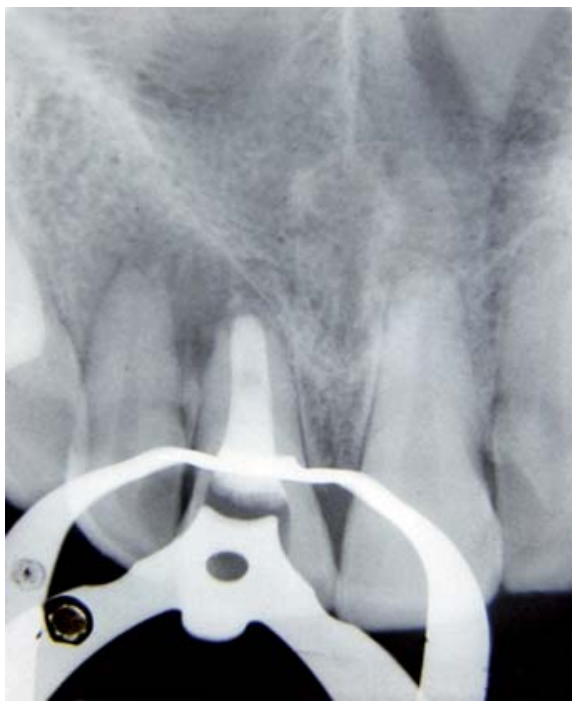

Fig. 4: Postobturation radiograph (Case 1)

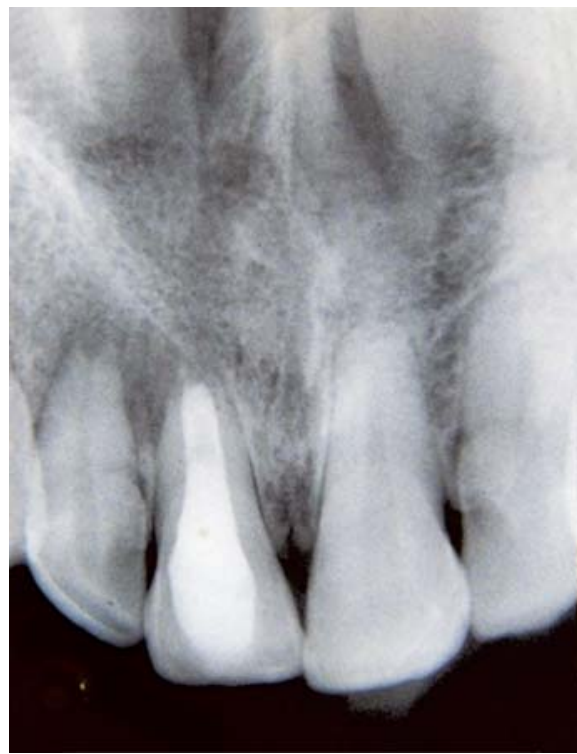

Fig. 5: 6-month follow-up radiograph

was dried with multiple absorbent points and a water-based calcium hydroxide dressing was placed. A ccess was seal ed with Cavit-G and patient was recalled.

One week later, tooth was again isolated and canal thoroughly irrigated with saline to remove any remnants of calcium hydroxide and $17 \%$ liquid EDTA (Smear Clear SybronEndo, CA, USA ) to remove smear layer. A fter drying canal, M TA (Dentsply Tulsa) pow der was mixed with distilled water which was then carried into canal with the help of amal gam carrier and packed to form an apical plug of approximately $5 \mathrm{~mm}$ (Fig. 3) under operating microscope (12x magnification). Over this moist cotton pellet was placed and access cavity was sealed. Next day, cotton pellet was removed and canal was thoroughly dried with multiple absorbent points. Plugger was used to check the consistency of M TA and to examine if it was completely set. Subsequently, backfill was performed using thermoplasticized gutta-percha (Elements Obturation System, SybronEndo, CA, USA). Postobturation radiograph (Fig. 4) 
confirmed the completion of endodontic therapy. A 6-month follow-up radiograph revealed decrease in apical radiolucency (Fig. 5).

\section{Case Report 2}

A 19-year-old female patient came to the Department of Conservative Dentistry and Endodontics, KLEVK Institute of Dental Sciences, B elgaum, Karnataka, India, with the chief complain of fractured maxillary left central incisor. The patient reported that the trauma occurred about 11 years back and no treatment had been performed. Clinical examination revealed crown fracture exposing pulp of maxillary left central incisor. The tooth failed to respond to thermal as well as electric pulp test. Periapical radiograph reveal ed immature21 with open apex (Fig. 6). Root canal treatment using M TA as an apical plug followed by obturation with thermoplasticized gutta-perchawas planned.

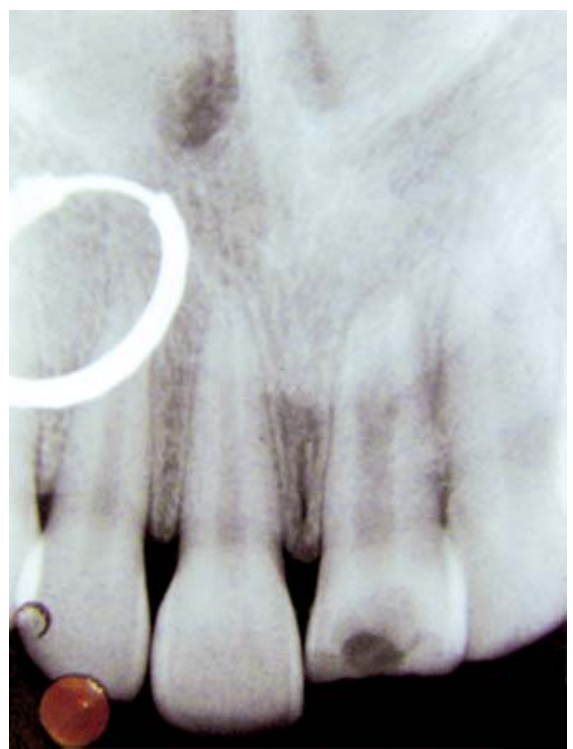

Fig. 6: Preoperative periapical radiograph (Case 2)

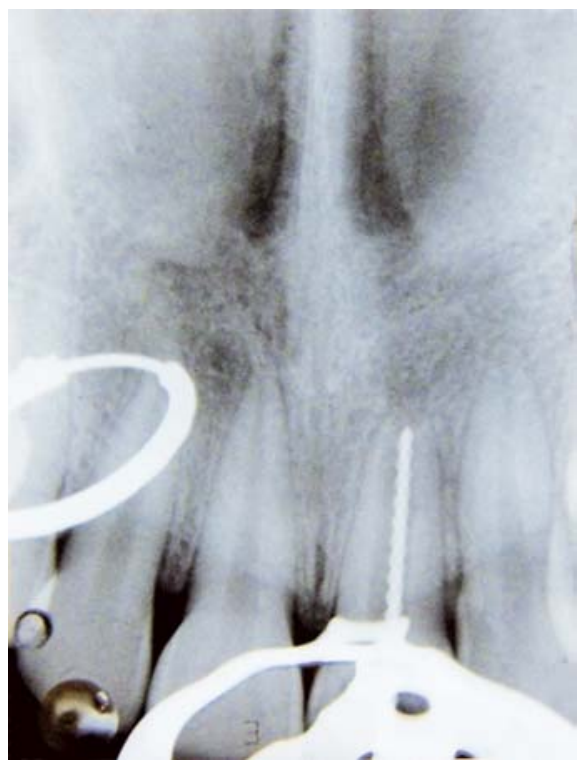

Fig. 7: Working length radiograph (Case 2)
Rubber dam was applied and a conventional endodontic access was prepared with 21. Working length (Fig. 7) was calculated as in the above case followed by gentle instrumentation with $\# 80 \mathrm{H}$-file in a circumferential manner along with continuous irrigation with 3\% sodium hypochlorite. Canal was dried and a water-based calcium hydroxide dressing was placed. Patient was recalled after a week when thorough irrigation was carried out to remove any remnants of calcium hydroxide. Canal was dried and M TA (D entsply Tulsa) was placed into the canal to form an apical plug of approximately $5 \mathrm{~mm}$ (Fig. 8) similar to case presented before. Over this moist cotton pellet was placed and access cavity was sealed. Next day, backfill was performed using thermoplasticized gutta-percha (Elements Obturation System, SybronEndo, CA, USA ). Postobturation radiograph (Fig. 9) was taken to confirm the completion of endodontic therapy. The patient is completely asymptomatic and has been called for follow-up.

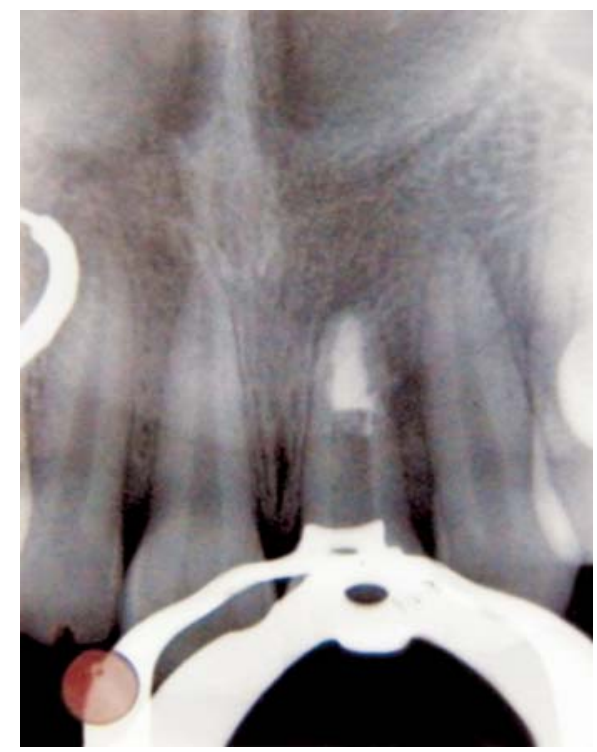

Fig. 8: Apical plug of MTA (Case 2)

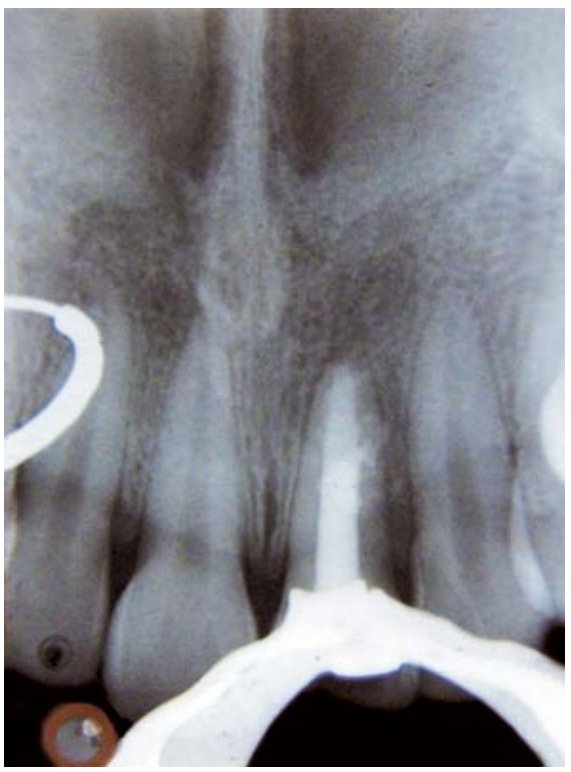

Fig. 9: Postobturation radiograph (Case 2) 


\section{DISCUSSION}

Incomplete root development requires special attention and treatment plan. In such cases, the canal remains large with thin and fragile walls, and the apex architecture is divergent. These features make instrumentation of the canal difficult and hinder the formation of an adequate apical stop. As a result, it is imperative to create an artificial apical barrier or to induce the closure of the apical foramen with calcified tissue in order to allow for condensation of the root filling material and to create an adequate apical seal. ${ }^{16-18}$ Calcium hydroxide has been the material of choice for induction of apical calcific barrier. B ut the long time required by calcium hydroxide to induce rootend closure limits its use. Also, extended use of calcium hydroxide makes the root prone to fracture. MTA may be an appropriate alternative for performing this procedure with predictable results. MTA has an ability to facilitate normal periradicular architecture by inducing hard-tissue barrier. ${ }^{19}$ Its excellent biocompatibility, ability to set in presence of blood, possibility to restore teeth with a minimal delay without changing the mechanical properties of dentine, as seen with prolonged use of calcium hydroxide, make it even more advantageous. In general, the outcomes in the present two case reports are similar to previously reported cases of successful MTA apical plug procedures in teeth with necrotic pulps and open apices. $^{8,9,19}$

In the present case reports, after access preparation, working length was calculated using paper point method, since apex locators have shown inaccurate results in open apices. ${ }^{20}$ Instrumentation was done with \#80 H-file circumferentially to effectively clean the wide canal without applying excess pressure to prevent fracture of thin dentinal walls. In between, irrigation was done with $3 \% \mathrm{NaOCl}$. W ater-based calcium hydroxide was placed to ensure rapid and complete disinfection. One week later, calcium hydroxide was removed and 4 to $5 \mathrm{~mm}$ MTA plug was formed in apical area to form a hard barrier against which obturation material could be placed. O bturation was completed with thermoplasticized gutta-percha, since it can be placed without applying any compaction forces on thin dentinal walls in contrast to lateral condensation method. A fter 6 months, both teeth were clinically asymptomatic and radiographic examination showed the dramatic regeneration of periradicular tissues. The use of operating microscope was very much hel pful to place M TA barrier precisely in the apical area.

\section{CONCLUSION}

These results show that apexification in one visit, by placing an apical plug of M TA, is a predictable and reproducible clinical procedure. M ore investigations are necessary about the biological process of apexification, and the activity of M TA in contact with cells, especially its potential role in cell differentiation and wound healing.

\section{REFERENCES}

1. Selter S. Endodontology: Biologic considerations in endodontic procedures (2nd ed). Philadel phia: L ea and Febiger 1988.

2. A merican A ssociation of Endodontists. Glossary of Endodontic Terms (7th ed). Chicago: A merican A ssociation of Endodontists 2003.

3. Rafter M. A pexification: A review. Dental Traumatology 2005;21:1-8.

4. Sheehy EC, Roberts GJ. U se of calcium hydroxide for apical barrier formation and healing in nonvital immature permanent teeth: A review. B ritish Dental J ournal 1997;183:241-46.

5. Magura M E, K afrawy A H, Brown CE Jr, Newton C. Human sal iva coronal microl eakage in obturated root canals: A $n$ in vitro study. J ournal of Endodontics 1991;17:324-31.

6. Morse DR, O'L arnic J, Y esilsoy C. A pexification: R eview of the literature. Quintessence International 1990;21:589-98.

7. Torabinejad M, Chiavian N. Clinical application of mineral trioxide aggregate. Journal of Endodontics 1993;25:197-205.

8. Shabahang S, Torabinejad M. Treatment of teeth with open apices using mineral trioxide aggregate. Practical Periodontics and A esthetic Dentistry 2000;12:315-20.

9. $M$ aroto $M, B$ arberia $E$, Planells $P, V$ era $V$. Treatment of a nonvital immature incisor with mineral trioxide aggregate (M TA). Dental Traumatology 2003;19:217-21.

10. Koh ET, M CDonald F, Pitt Ford TR, Torabinejad M. Cellular response to mineral trioxide aggregate. J ournal of Endodontics 1998;24:543-47.

11. Holland R, Filho JA, de Souza V, N ery M J, B ernabe PF, J unior ED. M ineral trioxide aggregate repair of lateral root perforations. J ournal of Endodontics 2001;27:281-84.

12. Torabinejad M, Hong CU, Pitt Ford TR, K ettering JD. A ntibacterial effects of some root end filling materials. J ournal of Endodontics 1995a;21:403-06.

13. A rens $D E$, Torabinejad $M$. Repair of furcal perforations with mineral trioxide aggregate: T wo case reports. Oral Surgery, Oral Medicine, Oral Pathology, Oral Radiology, and Endodontics 1996;82:84-88

14. Torabinejad $M$, Smith PW, K ettering JD, Pitt Ford TR. Comparative investigation of marginal adaptation of mineral trioxide aggregate and other commonly used root-end filling materials. J ournal of Endodontics 1995b;21:295-99.

15. A minoshariae A, Hartwell GR, M oon PC. Placement of mineral trioxide aggregate using two different techniques. Journal of Endodontics 2003;29:679-82.

16. L eonardo M R, da Silva LA, L eonardo R deT, et al. Histological evaluation of therapy using a calcium hydroxide dressing for teeth with incompletely formed apices and periapical lesions. J Endod 1993:19:348-52.

17. Felippe M C, Felippe WT, M arques M M , et al. The effect of the renewal of calcium hydroxide paste on the apexification and periapical healing of teeth with incomplete root formation. Int Endod J 2005;38:436-42.

18. Dominguez Reyes A, M unoz M unoz L , A znar M artin T. Study of calcium hydroxide apexification in 26 young permanent incisors. Dent Traumatol 2005;21:141-45.

19. Giuliani $V, B$ accetti $T$, Pace $R$, et al. The use of MTA in teeth with necrotic pulps and open apices. Dent Traumatol 2002;18:217-21.

20. Tosun G, Erdemir A, Eldeniz A U, Sermet U, Sener $Y$. A ccuracy of two electronic apex locators in primary teeth with and without apical resorption: A laboratory study. Int Endod J 2008;41: 436-41. 